\title{
Preterm Ovarian Hyperstimulation Syndrome: A Clinical Presentation of Three Cases
}

\author{
Ivana Vorgucin $^{1 *}$, Dragan Katanic ${ }^{1}$, Branka Kovacevic ${ }^{1}$, Melanija Vislavski ${ }^{1}$, Ivana Bajkin ${ }^{2}$, Sandra \\ Stankovic ${ }^{3}$
}

${ }^{1}$ Institute for Children and Youth Health Care of Vojvodina, Novi Sad, Faculty of Medicine, University Novi Sad, Serbia ${ }^{2}$ Clinical Center of Vojvodina, Novi Sad, Faculty of Medicine, University Novi Sad, Serbia

${ }^{3}$ Children Clinic Nis, Serbia

*Corresponding author: Ivana Vorgucin, PhD, Institute for Children and Youth Health Care of Vojvodina, Novi Sad, Faculty of Medicine, University Novi Sad, Hajduk Veljkova 10, Serbia, Tel:+381638688583; E-mail: IVANA.VORGUCIN@mf.uns.ac.rs, vorgucin@nspoint.net

\begin{abstract}
Objective: Preterm Ovarian Hyperstimulation Syndromeis a rare condition, presented with swollen genitalia in preterm female infants. The laboratory results detect elevated levels of estradiol and gonadotropins, while an ultrasound examination often verifies ovarian cysts. The cause of the condition is an immature hypothalamic-pituitary-gonadal axis. Methods/Results/Conclusion. We are going to show a mini series of three patients with preterm ovarian hyperstimulation syndrome with different clinical courses.
\end{abstract}

Keywords: Preterm ovarian hyperstimulation syndrome; Swollen genitalia; Preterm infants; Ovarian cysts

\section{Introduction}

Preterm Ovarian Hyperstimulation Syndrome (POHS) is a rare condition found in preterm female infants, born between 24 - 31 gestation week (GW). Prof. Sedin et al. described this condition in 1985[1]. The condition is presented with swollen genitalia, both labia majora and labia minora, clitoris and swollen pubic area, as well as the anterior part of the thighs. Vaginal bleeding and enlarged breasts appear rarely. The laboratory analyses confirm elevated levels of estradiol and gonadotropins, follicle-stimulating hormone (FSH) and luteinizing hormone ( $\mathrm{LH})$. A US examination of inner genitalia often reveals ovarian cyst(s). Ovarian cysts appear in 30-35\% of the patients with this condition, with more than half of the cysts regressing spontaneously. If a cyst is large, i.e. $>30-40 \mathrm{~mm}$, it is necessary to have surgical and US monitoring and possible surgical treatment because of the risk of the cyst twisting[2,3]. The immaturity of the hypothalamic-pituitary-gonadal (HPG) axis and the disruption of the negative feedback loop of placental hormones are the main causes of this condition. Furthermore, physiological elevation of the levels of gonadotropins and estradiol and subsequent gradual normalization appear in accordance with gestational age. In preterm female infants, elevated levels of gonadotropins appear because of still underdeveloped ovaries. In addition, it has been established that the genitalia swelling is affected by elevated levels of vascular endothelial growth factors, secreted from granulosa and ovarian theca cells. Clinical and laboratory results are gradually normalized with the maturation of the HPG axis[4-6].

\section{Case 1}

A female preterm infant, born in GW 25 1/7, with birth weight (BW) of $740 \mathrm{gr}$ and Apgar Score (AS) 5/6. Due to her prematurity, the baby was hospitalized during the first three months of her life and monitored by a multidisciplinary team because of bronchopulmonary dysplasia (BPD), patent ductus arteriosus (PDA) and gastroesophageal reflux (GER). At the age of 4 months, corrected age (CA) 2 weeks, she was hospitalized due to vaginal bleeding that lasted two days. An examination confirmed the swelling of the pubic area, vulvar swelling and swollen clitoris, with palpable glandular breast tissue of $1 \mathrm{~cm}$ (Figure 1). A CBC test was conducted, alongside the analyses of coagulation mechanism, albumin and urine and the results came back clear. Elevated levels of estradiol and gonadotropins were detected (Figure 2, 3), with normal values of $17 \mathrm{OH}$ progesterone, AFP and betaHCG and normal female karyotype. A US of inner genitalia verified a multiseptated $16-\mathrm{mm}$ cyst on the right ovary. Further monitoring until the child was 11 months old revealed that the genitalia swelling had subsided and completely regressed (Fig.

\section{Received date: February 22, 2018 \\ Accepted date: June 15, 2018 \\ Published date: June 18, 2018}

Citation: Vorgucin., I., et al. Preterm Ovarian Hyperstimulation Syndrome: A Clinical Presentation of Three Cases. (2018) J Gynecol Neonatal Biol 4(1): 7-14.

Copyright: Ce 2018thorgucin, I. This is an Open access article distributed under the terms of Creatiye-6ommons Attribution 4.0 Internati 
1), the levels of estradiol and gonadotropins had gradually normalized, while the ovarian cyst reabsorbed spontaneously. We have a written inform consent from parents for publishing and use a photograph.

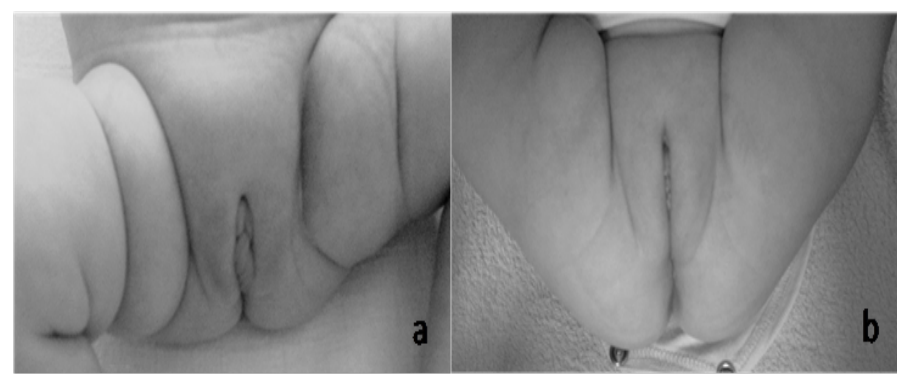

Figure 1: photograph of the genitalia of premature infants with POHS case 1 ; a) prominent swelling of genitalia and anterior part of the thighs b) normal appearance of genitalia at the age of 11 months

\section{Case 2}

A female preterm infant, born in GW 25 4/7, with BW 1000 gr and AS $2 / 5 / 10$. Due to her prematurity, the baby was hospitalized and monitored because of BPD, intracerebral hemorrhage (ICH), foramen ovale apertum (FOA) and retinopathy of prematurity (ROP). At the age of 4 months (CA 2 weeks), swellings occurred in the region of genitalia, suprapubic region and the anterior part of the thighs. Elevated levels of estradiol and gonadotropins were detected (Figure 2, 3), with elevated values of $17 \mathrm{OH}$ progesterone $7,34 \mathrm{ng} / \mathrm{ml}(\mathrm{nv}>3,1)$ and regular values of albumin, $\mathrm{Na}, \mathrm{K}$, glycaemia, testosterone and normal female karyotype. Some US verified cysts on both ovaries, on the left $27,5 \mathrm{~mm}$ with smaller cysts in the lumen and on the right $37 \mathrm{~mm}$ (Figure 4). The swelling of genitalia later subsided, the levels of estradiol, $17 \mathrm{OH}$ progesterone and gonadotropin gradually decreases, while the cysts remained present on both ovaries. This patient needs further monitoring.

We have a written inform consent from parents for publishing and use a photograph.

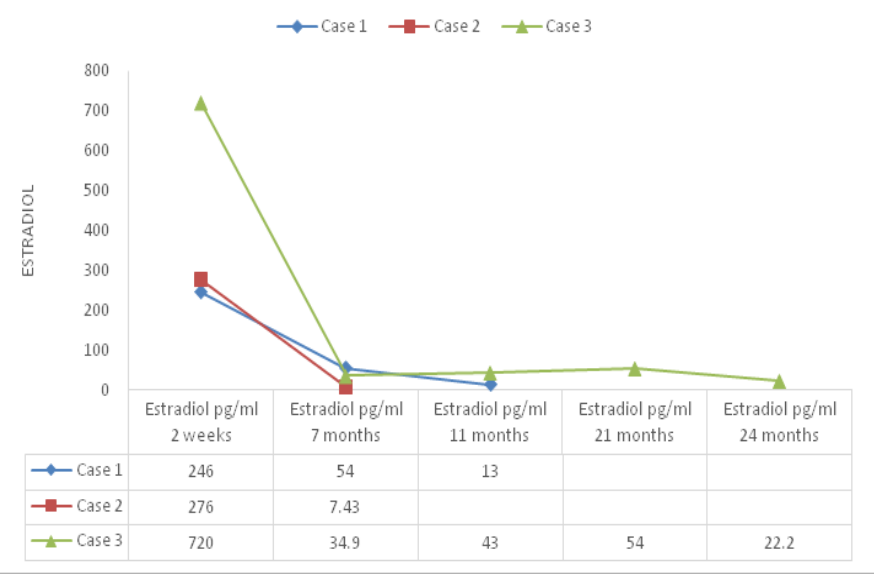

Figure 2: Estradiol levels in three patients

\section{Case 3}

A preterm female infant, born in GW 33 1/7, with BW $1590 \mathrm{gr}$ and AS 7/8 underwent a surgery of bilateral inguinal hernia at the age of three weeks. During the surgery, both ovaries were returned to their original position and an endocrinologist was consulted because of the dysmorphic genitalia. An examination confirmed swollen genitalia, particularly the clitoris, while lab- oratory tests showed elevated levels of estradiol and gonadotropins (Figure 2, 3), with normal values of tumor markers and normal karyotype. A US revealed a large multiseptated cyst on the right ovary, $37 \times 30 \mathrm{~mm}$, and a smaller cyst on the left ovary, $19 \times 19 \mathrm{~mm}$. Further monitoring showed that the swelling of genitalia quickly retracted and the level of gonadotropins was normalized, while the levels of estradiol were within referential values and the cysts became smaller. The level of estradiol and the US were completely normal at the end of the second year of life.

We have a written inform consent from parents for publishing and use a photograph.

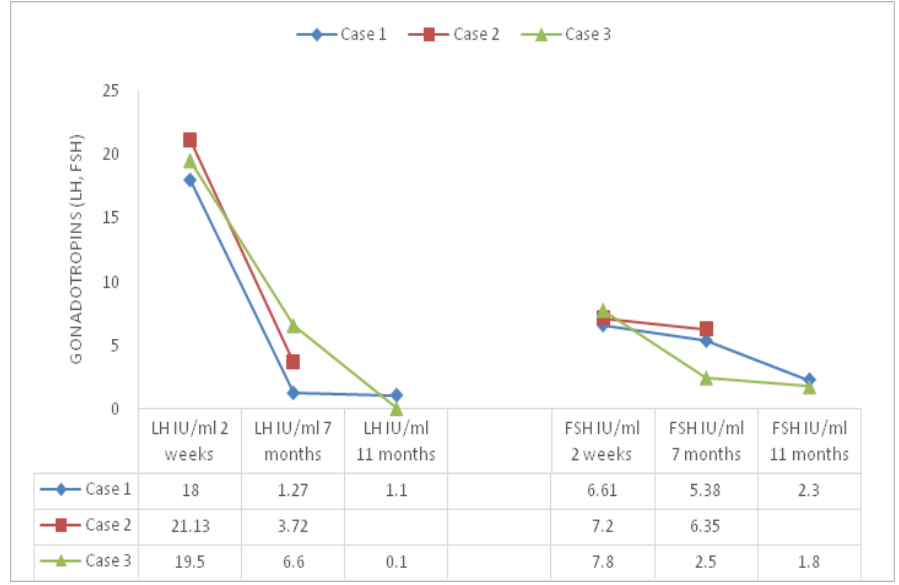

Figure 3: Levels of gonadotropins (LH, FSH) in three patients

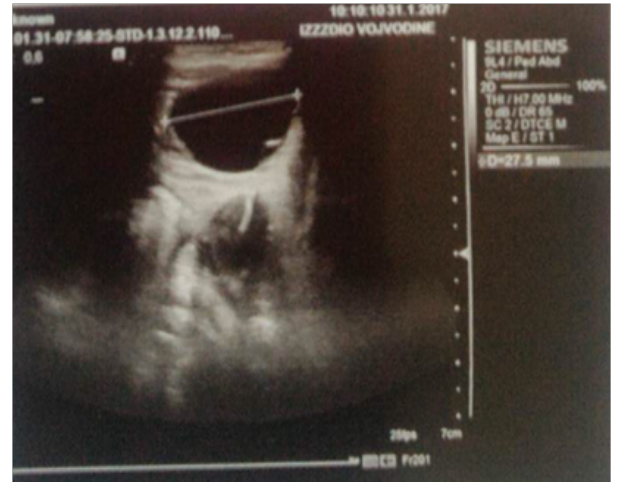

Figure 4: Longitudinal ultrasound view of the infant's pelvis with large right ovarian cyst - case 2

\section{Discussion}

The HPG axis is active at the middle of fetal period, while it is completely stable in the second half of fetal period due to the effect of placenta hormones. Right after the birth, the HPG axis becomes active and elevated levels of gonadotropins are present during the first three months. They start reducing grually until the sixth month, while increased values of FSH are sometimes present for 3 - 4 years even. Elevated levels of gonadotropins lead to maturation of ovarian follicle maturation and increased values of estradiol[7]. Both terms and preterm infants register elevated levels of gonadotropins at birth, but the values are higher in preterm infants. In preterm infants, the level of FSH reduces around the expected term, because follicles mature and the level of estradioreistelevated. This fact contributes to the theory that the immaty of the HPG axis prerm infants is one of the causes of rerfice levels of 
In 1985, professor Sedin et al. first described POHS in four preterm infants born at GW 24 - 28[1], while Starzyk et al. published nine case studies[3]. POHS develops due to the immaturity of the HPG axis and the disruption of the negative feedback loop of placental hormones. Furthermore, higher values of gonadotropins are registered in preterm female infants because of still insufficiently developed ovaries. It has also been established that swollen genitalia are also caused by high levels of vascular endothelial growth factors secreted from granulosa and ovarian theca cells. The maturation of the HPG axis gradually leads to normalization of clinical and laboratory results[4-6]. Besides swollen genitalia and ovarian cysts, clinical report rarely includes vaginal bleeding[2,9] and enlarged breasts, as registered in our Case 1. It is particularly important to know the clinical course with vaginal bleeding, since this condition does not require examination, but only monitoring. Two cases include preterm infants with menstrual bleeding at the age of 6 months (CA 2.5 months), where the results showed the activation of the HPG axis and elevated levels of estrogen, but without swollen genitalia[9]. Vaginal bleeding in neonatal period usually occurs immediately after birth, as a result of child's endometrium's exposure to mother's estrogens during the fetal period and the fact that placental hormones cease to have effect. In $3-5 \%$ of the cases, the bleeding is clearly noticeable, while in many more cases, around $25-60 \%$, bleeding is microscopic. Vaginal bleeding that appears later can be a consequence of many causes, such as trauma, local lesion, foreign body, praecox puberty, and it is important to be familiar with POHS because of differential diagnosis. Vaginal bleeding outside the neonatal period has so far not been reported in term infants and children small for gestational age (SGA), but only in preterm infants. Reports on POHS include both swollen genitalia and ovarian cysts[10-12] and when cysts retract the swelling of genitalia gradually decreases, which might indicate a potential role of vascular endothelial growth factors, secreted from granulosa and ovarian theca cells, in the creation of the syndrome[13]. A US often registers one or more smaller daughter cysts, alongside one large ovarian cyst[14,15]. The ovarian cysts have to be monitored with US examinations due to a potential risk of surgical complications. Apart from elevated levels of estradiol and gonadotropin in POHS, the literature very rarely describes elevated $17 \mathrm{OH}$ progesterone, as it was the case in our Case 2[16]. Swollen genitalia can lead to dysmorphic appearance, as in our Case 3, while further monitoring can reveal spontaneous retraction. After birth, estradiol levels fluctuate during the first months, which affects the cyclic maturation and atrophy of ovarian follicles. Higher levels of estradiol can prevail over longer periods and return to normal during the second year of life, as demonstrated in our Case 3[7]. Premature female infants are not exposed to high levels of estrogen at the end of pregnancy in the uterus and the mammary gland and the uterus are less stimulated than in term infants. That is the reason why the effects of elevated estrogen levels are much more visible in premature female infant and connected with enlarged mammary glands and uterus[17]. It is important to know the HPG axis in premature infants[18,19], as well as the clinical presentation of POHS, since unnecessary exams and treatments can be avoided[20]. Gynecological problems in infancy are rare and they belong to physiological-anatomic variants of genital development. Knowing POHS is important in the differential di- agnosis of swollen genitalia, clitoromegaly, premature puberty, ovarian cysts and vaginal bleeding. Neonatal care is improving, an increasing number of preterm infants manage to survive and we are seeing more patients with this condition.

\section{References}

1. Sedin, G., Bergquist, C., Lindgren, P.G. Ovarian Hyperstimulation Syndrome in Preterm Infants. (1985) Pediatr Res 19(6): 548-523.

Pubmed | Crossref $\mid$ Others

2. Altuntas, N., Turkyilmaz, C., Yuce, O., et al. Preterm ovarian hyperstimulation syndrome presented with vaginal bleeding: a case report. (2014) J PediatrEndocr Met 27(34): 355-358.

Pubmed | Crossref $\mid$ Others

3. Starzyk, J., Wojcik, M., Wojtys, J., et al. Ovarian hyperstimulation syndrome in newborns-a case presentation and literature review. (2009) Horm Res 71(1): 60-64.

Pubmed | Crossref | Others

4. Achermann, J.C., Hughes, I.A. Disorders of Sex Development. In: Melmed S, Polonsky KS, Reed Larsen P et al. (2011) Williams Textobookog Endocrinology, 12 th ed. Elsevier Saunders 886-933.

Pubmed | Crossref $\mid$ Others

5. Rosenfield, R.L., Cooke, D.W., Radovick, S. Puberty and its Disorders in the Female. In: Sperling MA, editor. (2014) Pediatric Endocrinology 4th ed. Elsevier Saunders 569-663. Pubmed | Crossref $\mid$ Others

6. Styne, D.M. Disorders of Puberty In: Styne DM, editor. Pediatric Endocrinology a Clinical Handbook. (2016) Springer 189-232.

Pubmed | Crossref $\mid$ Others

7. Kuiri-Hanninen, Sankilampi, U., Dunkel, L. Activation ofthe Hypothalamic-Pituitary-Gonadal Axis in Infancy; Minipuberty.(2014) Horm Res Paediatr 82(2):73-80.

Pubmed | Crossref | Others

8. Kurtogly, S., Bastug, O. Mini puberty and its interpretation. (2014) Turk Ped Ars 49(3):186-191.

Pubmed | Crossref | Others

9. Vogiatzi, M.G., Pitt, M., Oberfield, S., et al. Menstrual Bleeding as a Manifestation of Mini-Puberty of infancy in Severe Prematurity. (2016) J Pediatr 178: 292-295.

Pubmed | Crossref | Others

10. Esen, I., Demirel, F. Images in Clinical Medicine. Preterm Ovarian Hyperstimulation. (2015) N Engl J Med 372(24): 2336. Created with $\mid$ Others

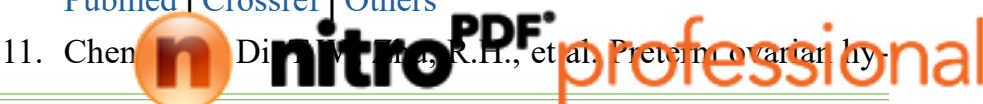


perstimulation syndrome: a case report and literature review. (2016) ZhonghuaErKeZaZhi 54(4): 283-286.

Pubmed |Crossref $\mid$ Others

12. Vochem, M. Ovarian hyperstimulation syndrome in preterm infants. (2002) Z Geburtshilfe Neonatol 206(4):156-160. Pubmed | Crossref | Others

13. Mosallanejad, A., Tabatabai, S., Shakiba, M., et al. A Rare Case of Ovarian Hyperstimulation Syndrome in a Preterm Infant. (2016) J ClinDiagn Res 10(11): SD07-SD08. Pubmed | Crossref | Others

14. Marinkovic, M., Rasmussen, M., Jones, K. Feminizing Changes in a Prematurely Born Infant. (2010) Clinical Pediatrics 49(2):188-189.

Pubmed | Crossref $\mid$ Others

15. Young Jung, M., Sung Son, O., Hyun Lee, J., et al. Preterm Ovarian Hyperstimulation Syndrome. (2015) Neonatal Med 22(4): 223-227.

Pubmed $\mid$ Crossref $\mid$ Others

16. Durst, M.A, Wicklow, B., Narvey, M. Atypical case of preterm ovarian hyperstimulation syndrome. (2017) BMJ Case Reports.

Pubmed | Crossref | Others

17. Kuiri-Hanninen, T., Kallio, S., Seuri, R., et al. Postnatal developmental changes in the pituitary-ovarian axis in preterm and term infant girls. (2011) J Clin Endocrinol Metab 96: 3432-3439.

Pubmed |Crossref $\mid$ Others

18. Greaves, R.F., Pitkin, J., Ho, C.S., et al. Hormone modeling in preterm neonates: establishment of pituitary and steroid hormone reference intervals. (2015) J Clin Endocrinol Metab100: 1097-1103.

Pubmed | Crossref | Others

19. Greaves, R.F., Zacharin, M.R., Donath, S.M., et al. Establishment of hormone reference intervals for infants born $<$ 30 weeks' gestation. (2014) Clin Biochem 47: 101-108. Pubmed | Crossref $\mid$ Others

20. de Lange, A.H., Bocca, G. Vaginal bleeding in a 4-monthold preterm girl: extreme minipuberty mimicking central precocious puberty. (2013) J Pediatr Endocrinol Metab 6:595-597.

Pubmed | Crossref | Others
Submit your manuscript to Ommega Publishers and we will help you at every step:

- We accept pre-submission inquiries

- Our selector tool helps you to find the most relevant journal

-We provide round the clock customer support

- Convenient online submission

- Thorough peer review

- Inclusion in all major indexing services

- Maximum visibility for your research

Submit your manuscript at OMMEgA Publishers

https:/Oraated withgaonline.org/submit-manuscript 